\title{
DIVERSIFICATION OF THE GLOBAL GREEN BOND MARKET
}

\section{MACIEJ PAWŁOWSKI}

University of Szczecin, Faculty of Management and Economics of Services, POLAND

email: maciej.pawlowski@usz.edu.pl

RECEIVED
ACCEPTED
JEL
CLASSIFICATION

KEYWORDS

ABSTRACT
18 January 2018

2 September 2018

$\mathrm{E} 44, \mathrm{~F} 34, \mathrm{G} 15, \mathrm{G} 23$

bonds, green bond market, green finance, financial markets, sustainable development, pro-ecological investments

Green Bonds emerged as a new form of environmental financing in 2007. While the green bond market is viewed as a niche in the global financial market, it has grown rapidly to nearly USD 900 billion in 2017. The aim of the article is to analyze and assess changes taking place in the structure of the global green bond market with particular emphasis on the diversification of issuers undertaking activity in this market area. The first part of the paper summarizes the general theory of green bonds. It also includes an exemplification of different types of green bonds and shows conditions which should be satisfied to call a bond the green bond. Afterward, the growth and diversification of the green bond market are shown and analyzed, what makes a field to draw some conclusions.

\section{Introduction}

In 2017, the green bond segment has been present in the structure of the global debt securities market for 10 years. Despite the relatively short history of existence, the market for these instruments is characterized by high dynamics of its value growth and evolutionary changes occurring in its area of operation. In 2017 alone, the value of the analyzed market increased by $30 \%$ compared to the previous year, reaching EUR 895 billion (compared to 
EUR 694 billion in 2016) (Boulle, 2017; Boulle, Frandon-Martinez, Pitt-Watson, 2016). In parallel to the above, the direction of capital allocation to various areas of pro-ecological activity is diversified, and what is more important the categories of issuers undertaking activity on the green bond market have clearly differentiated. The aim of the article is to analyze and assess the changes taking place in the structure of the global green bond market with particular emphasis on the subjective diversification of issuers undertaking activity in this market area. ${ }^{1}$

\section{Litepature review}

The literature on the subject has no clear definition of the concept of green bonds. The analysis of literature sources leads to the assertion that green bonds constitute a typical debt security meeting the standards of bonds, with the objective accompanying the issue of these instruments being their distinguishing feature (Gatti, Florio, 2018 , p. 208). On this ground, a discourse is born about a goal that would enable the bonds to be issued to get the status of green bonds. The problem of terminological nature is additionally complicated by the definition of climate bonds in both the subject literature and economic practice. The boundary between the indicated types of bonds green and climate - is not strict and easy to grasp. It turns out that the category of green bonds is treated both as a synonym of climate bonds (Lütken, 2015, p. 77; OECD, 2015, pp. 42-43; Cooperman, 2017, pp. 149-150; Wang, Stern, Limaye, Mostern, Zhang, 2013, p. 165), and as a separate class of debt securities.

The authors calling for differentness of the analyzed bond categories indicate that green bonds are a class of financial instruments used to finance projects aimed at environmental protection. Climate bonds, on the other hand, provide capital support for projects aimed at reducing greenhouse gas emissions and adapting the economy to climate change (Mackenzie, Ascui, 2009, p. 15; Kerste, Rosenboom, Sikken, Weda, 2011, p. 196; Nordic Council of Ministers, 2011, p. 47). In the light of the above, it can be assumed that the green bond category is meaningfully broader than the concept of climate bonds because the capital accumulated as part of issuing these instruments (green bonds) may be allocated to pro-environmental projects that have no impact on climate change (Kidney, Boulle, 2015, p. 582). As a consequence of this perception of mutual relations, it can be assumed that climate bonds are a specific type of debt issued within a broader group of financial instruments - green bonds.

However, the identity between green bonds and climate bonds is noticed by institutions that are active in the area of the green bond market - the World Bank (one of the main issuers of the securities of this category) and the Climate Bonds Initiative (an institution recommending green bond issue standards). In periodic reports and information brochures published by these institutions, green bonds are treated as instruments ensuring the collection of funds for financing projects aimed at environmental protection and combating climate change (World Bank, 2015, p. 23; www.climatebonds.net). In this approach - considered from the point of view of the issue's objective - the green bond category is a synonym for the concept of climate bonds (Cooperman, 2017, pp. 149-150; Hoffmann, 2015, p. 4).

1 The first ever green bond issue was carried out in 2007 by the European Investment Bank. The issued bonds were termed Climate Awaness Bonds, and their aim was to raise capital constituting the basis for loan financing investment projects in the field of renewable energy sources (wind, water, solar, geothermal) and improvement of energy efficiency (local heating, cogeneration, insulation of buildings, restrictions of energy losses in its distribution networks). The activity of the European Investment Bank not only enabled the collection of funds in the amount of EUR 600 million (Modak, 2018, p. 162), but also initiated a new segment of debt securities - green bonds. 
Difficulties in defining the boundary between investment projects designed to protect the environment and at the same time having no effect on climate change mean that for the purposes of this study, the concept of identity of green bonds and climate bonds has been accepted as valid. The adoption of such a position also results from the fact that the data being the subject of further analysis come from the Climate Bonds Initiative reports, and thus present aggregate figures, covering both the green bond and climate bond market, treating both instruments as equivalent.

According to the existing arrangements, the distinguishing feature of green bonds lies in the purpose for which the debt was issued. According to the methodology adopted by the Climate Bonds Initiative (Green Bonds Methodology, 2016), granting the debt securities the status of green bonds is based on a defined catalog of capital allocation directions, including financing of investment projects in the field of:

1. Renewable and alternative energy - investments in projects in the field of solar, wind, water, bio and geothermal energy, including expenditures for the construction of infrastructure, production, distribution and storage of energy from the above-mentioned sources.

2. Energy efficiency - construction and modernization of green residential and commercial facilities (buildings), development and implementation of energy-efficient products, processes and technologies, recovery of waste heat, reduction of greenhouse gas emissions.

3. Low-emission transport - expenditures for: construction of national and urban railway and goods systems, production of electric vehicles and vehicles powered by alternative fuels, rapid bus transit, bicycle transport, and aviation biofuels.

4. Sustainable water management - investments in: rainwater adaptation systems, treatment and recycling of water resources, immunization of the economy on variability of precipitation.

5. Waste management, recycling and pollution control - activities in the field of closed circulation economy aimed at reducing energy consumption and greenhouse gas emissions.

6. Sustainable agriculture and forestry, which concern problems of coal management, afforestation (above all but not only) of degraded areas, promotion and implementation of solutions in agriculture, which: favor reduction of carbon dioxide emissions and greenhouse gases, improve the economy's resilience to climate change, are focused on limiting the use of artificial fertilizers in agricultural production.

7. Infrastructure resistant to climate change, mainly in the area of weather anomalies.

The compliance of the bond issue declared by the issuer with the above-mentioned catalog is the basic premise for the classification of instruments and their inclusion in the group of green bonds. It should be mentioned that in the practice of the green bond market, two types of instruments of this type have developed - labelled green bonds and unlabelled green bonds. The first ones- labelled green bonds - represent a narrow group of debt instruments, in which the issuer not only maintained consistency of the issue's objective with the definitional assumptions of green bonds, but also assumed information obligations, in which it (on a current basis) publishes the direction and the scale of allocation of acquired capital. This is an important condition, as according to the Climate Bonds Initiative, the term green bonds can only be used for those instruments where $95 \%$ of the acquired capital is financed by the pro-environmental objective of the issue (described in points $1-7){ }^{2}$ The category of unlabelled

2 The category of labelled green bonds excludes instruments in which more than $5 \%$ of the value of inflows obtained from their issue is intended for general corporate purposes. 
green bonds, on the other hand, is a broader concept and covers instruments in which the acquired capital (in whole or in part) finances projects that benefit environmental protection and / or serves to build an economy resistant to climate change. Therefore, in the case of unlabelled green bonds, there are no restrictive classification conditions. It is only important that the capital accumulated on the bond market supports pro-ecological activity (not necessarily that specified in points $1-7) .^{3}$

\section{Method}

Analysis and evaluation of the process of diversifying the green bond market is based on secondary data statistics published by the Climate Bonds Initiative. It is a leading international institution whose aim is to promote projects that transform traditional economic systems into low-emission and climate-resilient economies. The strategy of the Climate Bonds Initiative includes a number of activities focused on: 1) determination of green bond issue standards and certification of issued instruments; 2) developing and popularizing solutions for the adaptation of green bonds to strategies for financing the activities of governments, financial institutions and enterprises in the real area; 3) ensuring transparency of the green bond market and stimulating its development through publication activity focused on reporting on qualitative and quantitative changes taking place within the green bond market (www.climatebonds.net).

As part of this study, the analysis covered the years 2012-2017 and accounted for internal and subjective diversification of the green bond market.

\section{Results}

The green bond market is characterized by impressive dynamics of its value increase (Figure 1). In the years 2012-2017, the cumulative annual growth rate (CAGR) of indebtedness related to the issue of these instruments amounted to almost 40\%. Comparing the value of the analyzed market recorded in 2017 (USD 895 billion) to 2012 (USD 174 billion), it turns out that there was a fivefold increase in the value of the green bond market in the period under consideration.

Different development trends in the individual segments can be observed while assessing the internal structure of the green bond market. It turns out that the category of labelled green bonds shows a clearly higher growth rate of its value, gaining at the same time an increasingly larger share in the structure of the green bond market (Table 1). In 2012 labelled green bonds represented only 1\% of the total value of the green bond market (USD 2 billion from USD 174 billion), and in 2017 this share was already 25\% (USD 221 billion from USD 895 billion). The sharp increase in the importance of these instruments results directly from the above-average growth rate of the value of labelled green bonds- the accumulated annual growth rate (CAGR) of this green bond segment, estimated for 2012-2017, is over $156 \%$.

\footnotetext{
${ }^{3}$ Methodology adopted by the Climate Bonds Initiative employs two basic boundary conditions for the classification of bonds as unlabelled green bonds: (1) there are market data on which the bond issue can be linked to the environmental problem (2) and the acquired capital finances this activity in $95 \%$.
} 


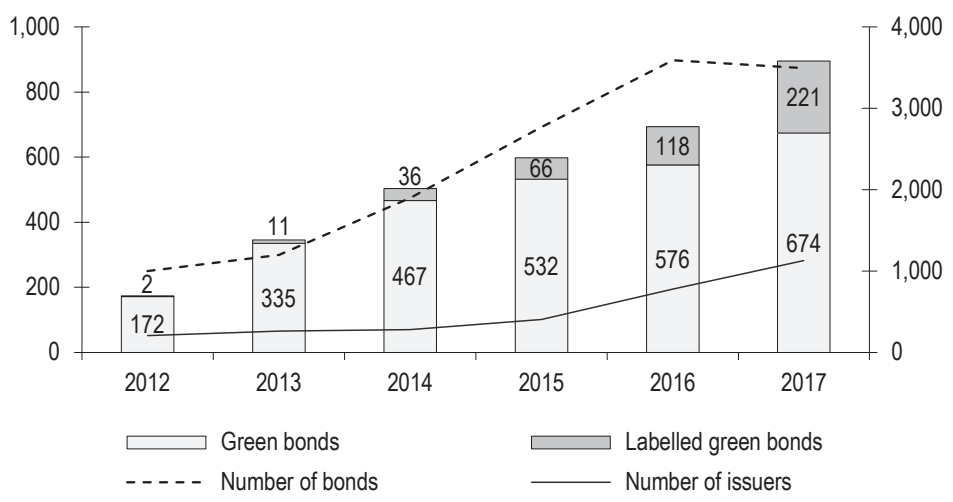

Figure 1. Value of the green bond market in USD billion (left axis), including the number of issuers and the number of issues (right axis)

Source: Padraig, Boulle, Kidney, Silver (2012); Padraig, Boulle, Kidney, Robins, Knight (2013); Boulle, Kidney, Oliver (2014); Olsen-Rong, House, Sonerud, Kidney (2015); Boulle (2017); Boulle, Frandon-Martinez, Pitt-Watson (2016).

Table 1. Indicators of the dynamics and structure of the green bond market (broken down into the segment of labelled green bonds and unlabelled green bonds) (\%)

\begin{tabular}{|c|c|c|c|c|c|c|}
\hline & 2012 & 2013 & 2014 & 2015 & 2016 & 2017 \\
\hline \multicolumn{7}{|c|}{ Green bond market } \\
\hline Market value growth dynamics (y/y) & & 98.85 & 45.38 & 18.89 & 16.05 & 28.96 \\
\hline CAGR & & & & & & 38.76 \\
\hline \multicolumn{7}{|c|}{ Labelled green bonds } \\
\hline Share of labelled green bonds in the green bond market & 1.15 & 3.18 & 7.16 & 11.04 & 17.00 & 24.69 \\
\hline Market value growth dynamics (y/y) & & 450.00 & 227.27 & 83.33 & 78.79 & 87.29 \\
\hline CAGR & & & & & & 156.26 \\
\hline \multicolumn{7}{|c|}{ Unlabelled green bonds } \\
\hline Share of unlabelled green bonds in the green bond market & 98.85 & 96.82 & 92.84 & 88.96 & 83.00 & 75.31 \\
\hline Market value growth dynamics (y/y) & & 94.77 & 39.40 & 13.92 & 8.27 & 17.01 \\
\hline CAGR & & & & & & 31.41 \\
\hline
\end{tabular}

Source: own study based on Climate Bonds Initiative data.

As a consequence of the above, the share of the unlabelled green bonds segment in the green bond market has been gradually decreasing - from over $98 \%$ recorded in 2012 to $75 \%$ in 2017 . At the same time, the dynamics of the growth of the value of the examined market is observed, which in average annual terms (measured with the CAGR index) amounted to just over 31\%. Parallel to the changes taking place in the internal structure of the green bond market, there are significant changes in the subjective structure of operating issuers (Figure 2). 


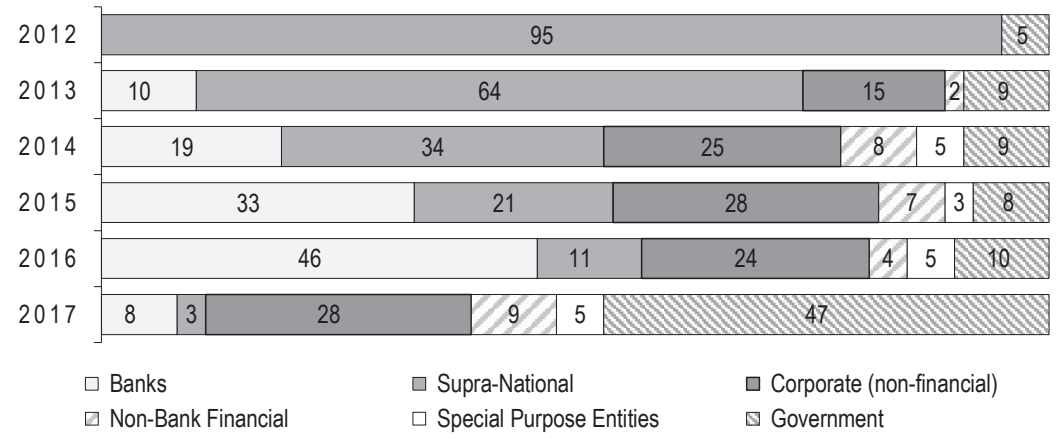

Figure 2. Structure of issuers on the green bond market (\%)

Source: Padraig, Boulle, Kidney, Silver (2012); Padraig, Boulle, Kidney, Robins, Knight (2013); Boulle, Kidney, Oliver (2014); Olsen-Rong, House, Sonerud, Kidney (2015); Boulle (2017); Boulle, Frandon-Martinez, Pitt-Watson (2016).

According to the existing findings, the green bond market was initiated through issues made by transnational financial institutions. ${ }^{4}$ This brought permanent consequences to the subjective structure of issuers present on this market, because until 2013 the green bond market was created by issues by transnational financial institutions with a small (5\%) share of issuers representing local government. The process of diversifying the group of issuers undertaking activity in the field of green bond issues has been observed since 2013 and it should be emphasized that the diversification of the subjective structure of the market is quite clear. It turns out that during the analyzed period, the importance of supranational financial institutions in shaping the value of the green bond market has decreased dramatically (from 95\% in 2012 to 3\% in 2017). At the same time, based on the presented statistics, three main categories of issuers can be distinguished, which can be attributed to a significant share in shaping the value of the green bond market - banks, enterprises (non-financial) and government authorities, which in total account for $83 \%$ of the value of the analyzed market.

\section{Conclusions}

The issue of green bonds is certainly an instrument for diversifying the sources of financing the borrowing needs of a diverse group of entities, at the same time fostering diversification of the investor base. A particular asset of the activity undertaken in the green bond market is the linking of financial aspects with the concept of sustainable development (highly appreciated and of huge interest for potential investors). Linking both elements not only creates a positive image of the issuer among the market participants, leading to the recognition of benefits from reputation and strengthening of the market position, but it also intensifies the transformation of economic systems into a lowemission and climate resilient model (by providing sources of financing for environmental projects).

The statistics analyzed in the present study reveal the need for a separate segment dedicated to financing pro-ecological activities. This statement is justified not only in the indicators characterizing the increase in the value

${ }^{4}$ In 2007, historically, the first issue of bonds was carried out by the European Investment Bank. In the following year, the World Bank joined the group of green bond issuers by issuing a debt issue to finance the needs of Scandinavian investment funds in the scope of financing climate projects, and in 2010 subsequent issues of green bonds were carried out by the European Bank for Reconstruction and Development and the International Finance Corporation. 
of the green bond market, but also in the diversification of the group of entities undertaking emission activity. A clear and progressive diversification of the entity structure of the green bond market indicates that there is a growing need to finance projects that protect the natural environment. What's more, it also signals a growing awareness of economic operators in the need to balance the demand of modern societies with the exploitation of natural resources and its negative impact on the environment and climate change.

\section{References}

Boulle, B. (2017). Bonds and Climate Change. The State of the Market 2017. Retrieved from: https://www.climatebonds.net/files/files/ CBI-SotM_2017-Bonds\%26ClimateChange.pdf.

Boulle, B., Kidney, S., Oliver, P. (2014). Bonds and Climate Change. The State of the Market 2014. [Retrieved from: https://www. climatebonds.net/files/post/files/cb-hsbc-15july2014-a3-final.pdf.

Boulle, B., Frandon-Martinez, C., Pitt-Watson, J. (2016). Bonds and Climate Change. The State of the Market 2016. Retrieved from: https://www.climatebonds.net/files/files/reports/cbi-hsbc-state-of-the-market-2016.pdf.

Cooperman, E.S. (2017). Managing Financial Institutions: Markets and Sustainable Finance. New York: Routledge.

Gatti, S., Florio, A. (2018). Issue spread determinants in the green bond market: The role of second party reviews and of the Green Bond Priciples. In: S. Boubaker, D. Cumming, D.K. Nguyen (eds.), Research Handbook of Finance and Sustainability. Northampton: Edward Elgar Publishing.

Green Bonds Methodology (2016). Retrieved from: https://www.climatebonds.net/files/files/Green\%20Bond\%20Methodology\%202017. pdf.

Hoffmann, M. (2015). The Need for Green Covenants. Regulating the Green Bond Market. London: London School of Economics and Political Science.

Kerste, M., Rosenboom, N., Sikken, B.J., Weda, J. (2011). Financing Sustainability: Insights for Investors, Corporate Executives, and Policymakers. Amsterdam: VU University Press.

Kidney, S., Boulle, B. (2015). The Opportunity for Bonds to Address the Climate Finance Challenge. In: K. Wendt (ed.), Responsible Investment Banking: Risk Management Frameworks, Sustainable Financial Innovations and Softlaw Standards. Switzerland: Springer.

Lütken, S.E. (2015). Financial Engineering of Climate Investment in Developing Countries. London: Anthem Press.

Mackenzie, C., Ascui, F. (2009). Investor leadership on climate change: an analysis of the investment community's role on climate change, and snapshot of recent investor activity. UNEP Finance Initiative and UNPRI.

Modak, P. (2018). Enviromental Management Towards Sustainability. Boca Raton: CRC Press Taylor \& Francis Group.

Nordic Council of Ministers (2011). Nordic Perspectives on Carbon Market Mechanisms. Copenhagen: Nordic Council of Ministers.

OECD (2015). The role of institutional investors in financing sustainable energy infrastructure. In: Mapping Channels to Mobilise Institutional Investment in Sustainable Energy. Paris: OECD Publishing.

Olsen-Rong, T., House, K., Sonerud, B., Kidney, S. (2015). Bonds and Climate Change. The State of the Market 2015. Retrieved from: https://www.climatebonds.net/files/files/CBI-HSBC\%20report\%207July\%20JG01.pdf.

Padraig, O., Boulle, B., Kidney, S., Silver, N. (2012). Bonds and Climate Change. The State of the Market 2012. [Retrieved from: https:/l www.climatebonds.net/files/uploads/2012/05/CB-HSBC_Final_30May12-A3.pdf.

Padraig, O., Boulle, B., Kidney, S., Robins, N., Knight, Z (2013). Bonds and Climate Change. The State of the Market 2013. Retrieved from: https://www.climatebonds.net/files/uploads/2013/08/Bonds_Climate_Change_2013_A3.pdf.

Wang, X., Stern, R., Limaye, D., Mostern, W., Zhang, Y. (2013). Unlocking Commercial Financing for Clean Energy in East Asia. Washington DC: World Bank.

World Bank (2015). What are green bonds? Washington, DC: World Bank.

Cite this article aS:. Pawłowski, M. (2018). Diversification of the global green bond market. European Journal of Service Management, 3 (27/2), 331-337. DOI: 10.18276/ejsm.2018.27/2-40. 